\title{
Revision of Iranian Schoenlandella Cameron, 1905 (Hymenoptera, Braconidae, Cardiochilinae) with descriptions of two new species from Hormozgan province
}

\author{
Ilgoo Kang ${ }^{1}$, Ali Ameri ${ }^{2}$, Michael J. Sharkey ${ }^{3}$ \\ 1 Department of Entomology, Louisiana State University Agricultural Center, 404 Life Sciences Building, Baton Rouge, LA, 70803 USA \\ 2 Insect Taxonomy Research Department, Iranian Research Institute of Plant Protection, Agricultural Research Education and Extension \\ Organization (AREEO), Tehran, Iran \\ 3 The Hymenoptera Institute, 116 Franklin Ave., Redlands, CA, 92373, USA \\ http://zoobank.org/A6D5B80A-51AD-4337-803F-3B83E40D95B3 \\ Corresponding author: Ilgoo Kang (ikang1@Isu.edu)
}

Academic editor: Jose Fernandez-Triana • Received 25 May 2021 • Accepted 12 August 2021 • Published 20 August 2021

\begin{abstract}
The Iranian species of the genus Schoenlandella Cameron, 1905 are revised based on morphological characters. The current work provides a key to species of Iranian Schoenlandella and species descriptions of two new species: S. angustigena Kang sp. nov. and $S$. latigena Kang sp. nov. This work results in increasing the number of Iranian Schoenlandella species from one to three species.
\end{abstract}

\section{Key Words}

Old World, parasitoid wasp, taxonomy, Western Palearctic region

\section{Introduction}

The Islamic Republic of Iran (Iran) is located in the Western Palearctic region, and 26 Holdridge life zones exist in the country (Sanjerehei 2014). Approximately $40 \%$ of the country is in the subtropical latitudinal region and $\sim 80 \%$ of the country consists of periarid, semiarid, arid, and superarid life zones (Sanjerehei 2014). One of braconid subfamilies having the highest distribution in arid regions is Cardiochilinae Ashmead, 1900 (Dangerfield et al. 1999). Nine species of Cardiochilinae have been recorded from Iran, including just one species of Schoenlandella Cameron, 1905, S. deserta (Telenga, 1955) (Gadallah and Ghahari 2019). Among cardiochiline genera, Schoenlandella has the most species in arid areas, especially in the Afrotropical and Australian regions. For example, in Egypt, seven species of Schoenlandella have been recorded, which account for $\sim 13 \%$ of Schoenlandella species in the World (Edmardash et al. 2018). Despite the abundance of the members of the genus in other arid countries in the Afrotropical and Western Palearctic regions, no additional new species of Schoenlandella from Iran have been recorded.

In several collecting trips by the second author (AA) from 2013 to 2019, a total of forty cardiochiline specimens were collected. These specimens were sent to the first author (IK) and identified to the species-level using Dangerfield et al. (1999), Edmardash et al. (2018), Oltra and Falco (1997), and Telenga (1955). Fifteen specimens collected in Hormozgan province located in the south of Iran were confirmed as two new species of Schoenlandella based on morphological data. The characters of these two new species were compared with the characters of paratypes of two close Afrotropical species, S. testacea (Kriechbaumer, 1894) and S. variegata (Szépligeti, 1913). In the current paper, species descriptions of two new species are included along with images of diagnostic characters. Distribution maps of each species are created and provided. 


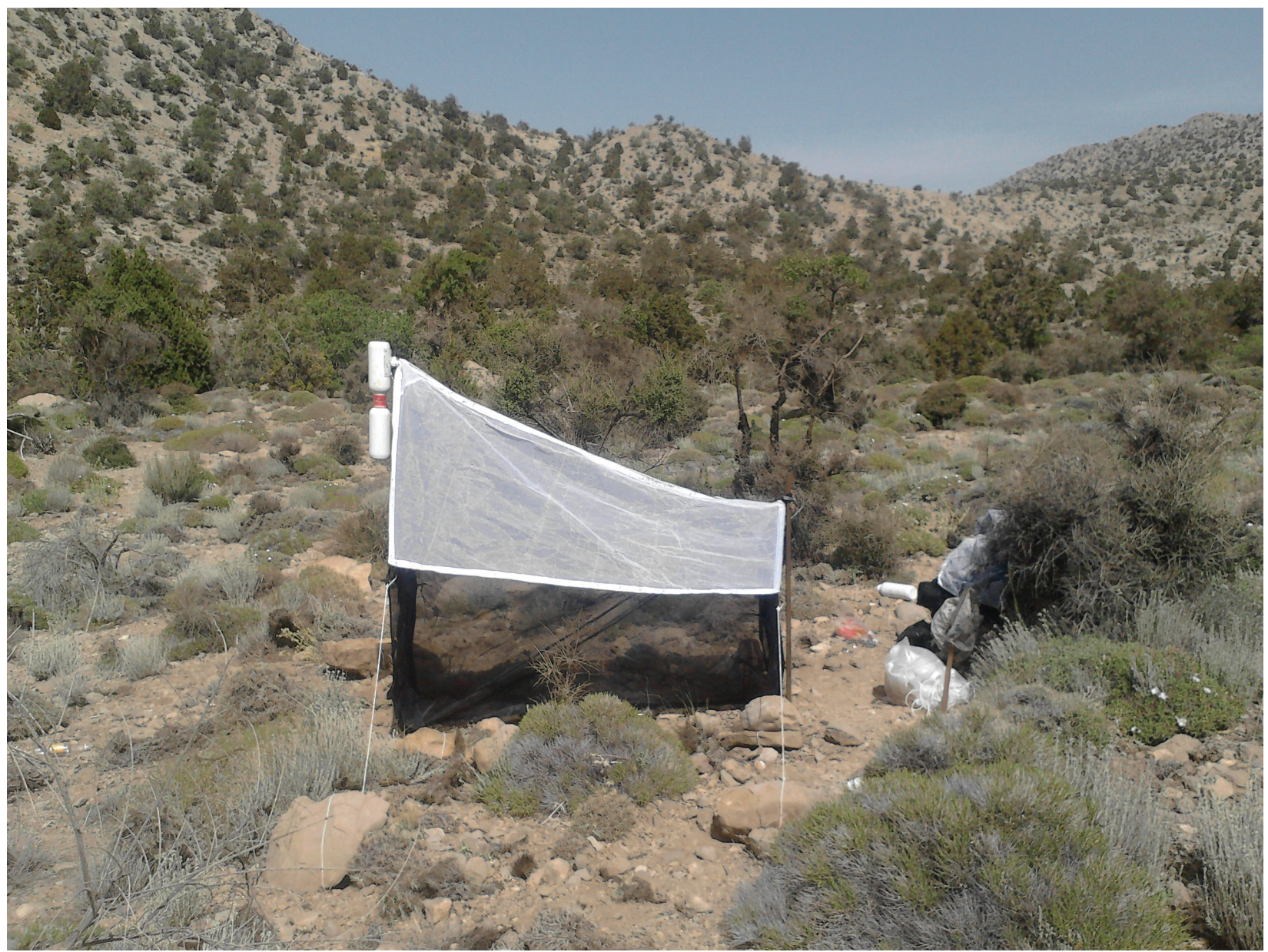

Figure 1. Malaise trap operating at one of the collecting sites in Hormozgan province.

\section{Methods}

\section{Specimen information}

Specimens used in the current work were collected by AA by Malaise traps from 2013 to 2019 in Hormozgan province (Fig. 1), Iran, and paratypes of S. testacea (Kriechbaumer, 1894) and S. variegata (Szépligeti, 1913) were borrowed from the Texas A\&M University Insect Collection (TAMU: College Station, Texas, USA). Holotypes and most paratypes of Iranian Schoenlandella species will be deposited in the Hayk Mirzayans Insect Museum of Iranian Research Institute of Insect Taxonomy Research Department, Iranian Research Institute of Plant Protection, Agricultural Research Education and Extension Organization (IRIPP: Tehran, Islamic Republic of Iran), and some paratypes will be housed in the Canadian National Collection of Insects (CNC: Ottawa, Ontario, Canada).

\section{Morphological analysis}

Morphological characters of all specimens were examined using a Leica MZ75 stereomicroscope. The morphological terms and terms for wing veins are based on Dangerfield et al. (1999), and Sharkey and Wharton (1997). Most terminology is available on the Hymenoptera Anatomy Consortium website (http://portal. hymao.org/projects/32/public/ontology/). The reference for terms of surface sculpturing used in the work is Harris (1979). Habitus photographs were taken using a Visionary Digital BK Plus imaging system (Dun, Inc.), equipped with a Canon EOS 5DS DSLR camera. The generated images were stacked using Zerene Stacker v.1.04 (Zerene Systems LLC.). Plates were prepared and edited using Adobe Photoshop CS 6 (Adobe Systems, Inc). Distribution maps of Schoenlandella species were created using QGIS 3.10.0 (QGIS Development Team 2019). Google maps were downloaded using the QuickMapServices plugin. Body parts of each species were measured via Adobe Photoshop CS 6 (Adobe Systems, Inc), and all measurements are given in millimeters. In the species descriptions, each number in parentheses indicates $0.01 \times$ the actual length, width, or height of each body part. For instance, 12 and 345 in parentheses (12:345) indicate $0.12 \mathrm{~mm}$ and $3.45 \mathrm{~mm}$, respectively. The following acronyms are used: POL: distance between posterior ocelli, T1 (first metasomal tergum), T2 (second metasomal tergum), and T3 (third metasomal tergum). 


\section{Results}

\section{Taxonomy}

\section{Schoenlandella Cameron, 1905}

Schoenlandella Cameron, 1905 (Cameron 1905a). Type Species: Schoenlandella nigromaculata Cameron, 1905 (Cameron 1905a) by subsequent designation by Viereck 1914 (synonymized with Cardiochiles Nees, 1819 by Szépligeti 1911). Removed from synonymy by Whitfield and Dangerfield (1997).

Ernestiella Cameron, 1905 (Cameron 1905b) synonymized with Schoenlandella Viereck, 1914. Type species: Ernestiella nigromaculata Cameron 1905 (Cameron 1905b).

Diagnosis. See Kang et al. (in prep.).

\section{Key to species of Iranian Schoenlandella}

1 A. Notauli smooth; forewing stigma entirely pale; metapleuron mostly smooth (Telenga 1955) ........ S. deserta (Telenga)

- $\quad$ B. Notauli crenulate (Figs 2B, 4B); BB. forewing stigma mostly melanic, basally pale (Figs 2A, 4A, 4F); BBB. metapleuron

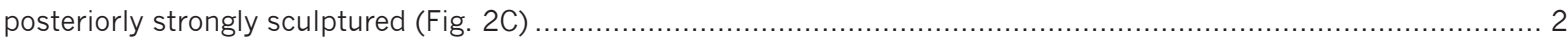

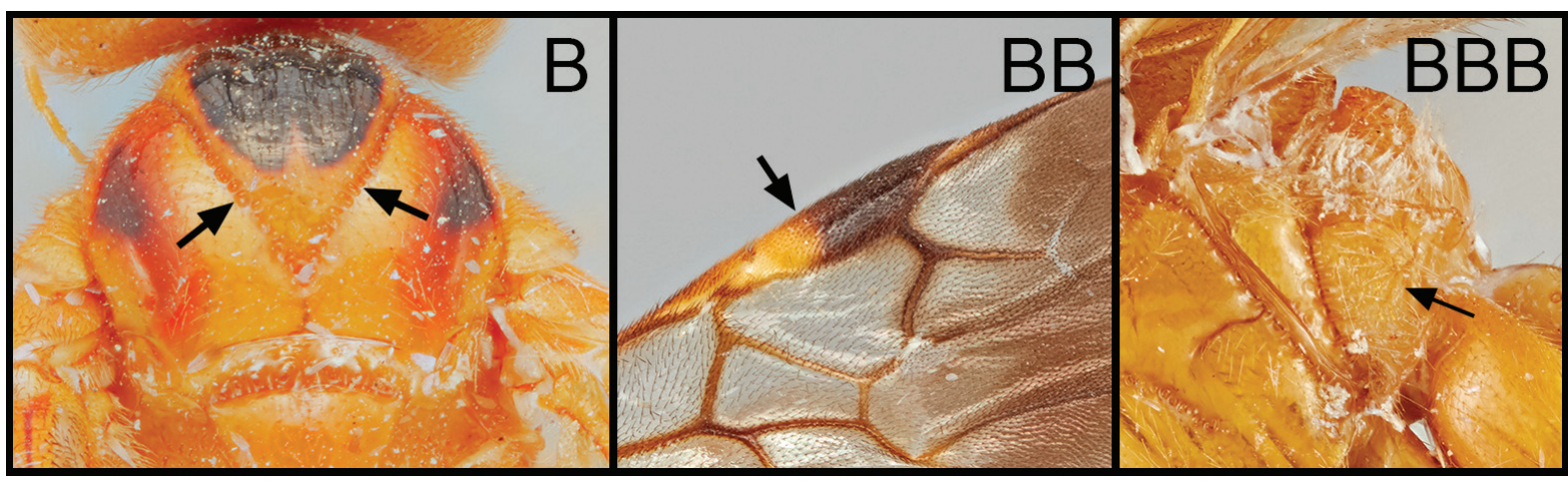

2 A. Length of gena longer than eye length in lateral view; AA. hind basitarsus shorter than combined length $2^{\text {nd }}-4^{\text {th }}$ tar someres

S. latigena sp. nov.

- $\quad$ B. Length of gena shorter than eye length in lateral view; BB. hind basitarsus longer than combined length $2^{\text {nd }}-4^{\text {th }}$ tar. someres...... S. angustigena sp. nov.

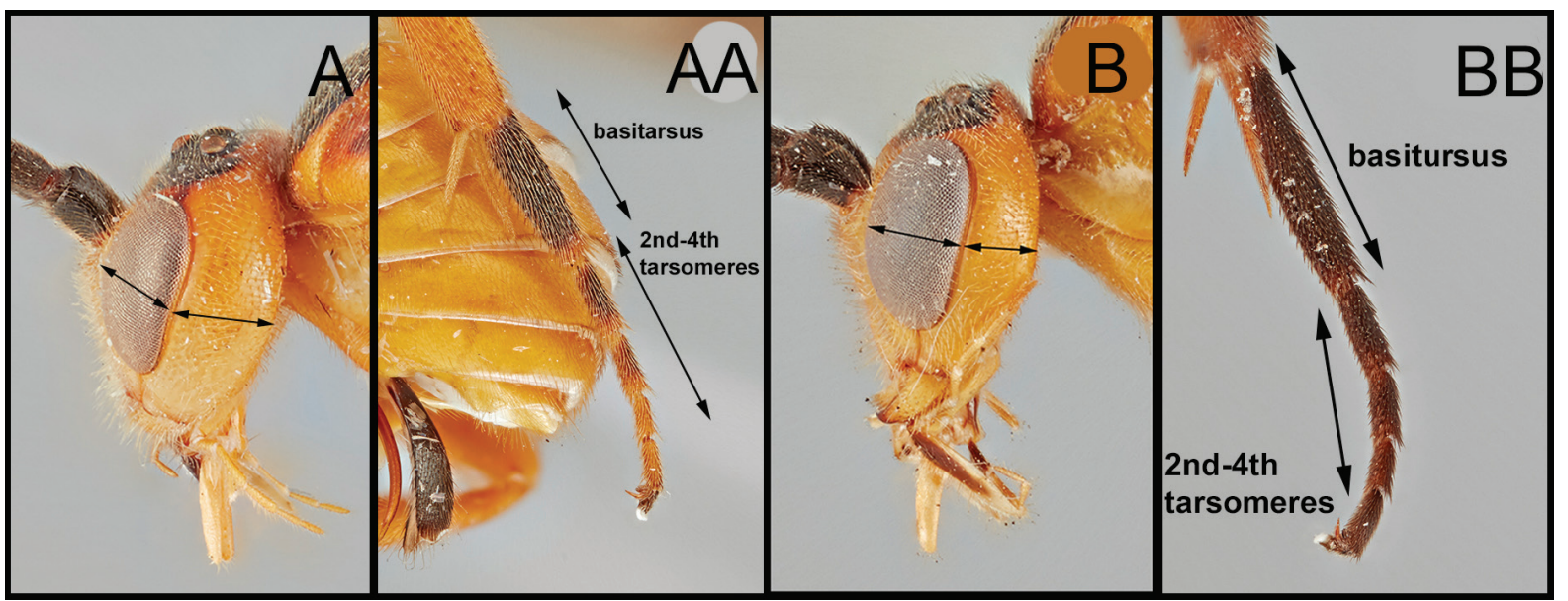

\section{Schoenlandella angustigena Kang, sp. nov.}

http://zoobank.org/F60B09B5-1B56-444D-B668-86AAB4F270A3 Fig. $2 \mathrm{~A}-\mathrm{G}$

Material examined. Holotype: IRAN $\bullet$, Fayrab, Roodan

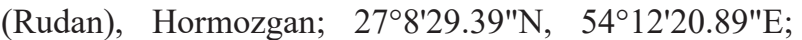
377 m; 23. II. 2017; Col. Ameri. Paratypes: Iran • 2ㅇ, $1 \hat{0}$, same as holotype. 2 , , Bazyarai, Minab, Hormozgan; 2710'36.83"N, 57²'12.44"E.; 34 m; 06. V. 2016; Col. Ameri. 1우, Boo moosa (Abu Musa), Hormozgan; 2552'52.37"N, 55¹'13.84"E; 9 m; 15. IV. 2016; Col.
Ameri. 19, Chelo, Minab, Hormozgan; 270 $3.62^{\prime \prime N}$, 56 58'49.71"E; 16 m; 05. IV. 2016; Col. Ameri. 1, female, Zakin, Bandar Abbas, Hormozgan; 2750'25.33"N, 56¹8'12.33"E; 1176 m; 09. IV. 2016; Col. Ameri.

Diagnosis. Schoenlandella angustigena sp. nov. can be distinguished from other Iranian Schoenlandella species by having the following combination of characters: gena apparently shorter than eye length in lateral view (Fig. 2C); hind basitarsus longer than combined length of $2^{\text {nd }-} 4^{\text {th }}$ tarsomeres (Fig. 2E). Hind wing mostly infuscate, hyaline at basal fourth, apically gradually darkened. S. angustigena 


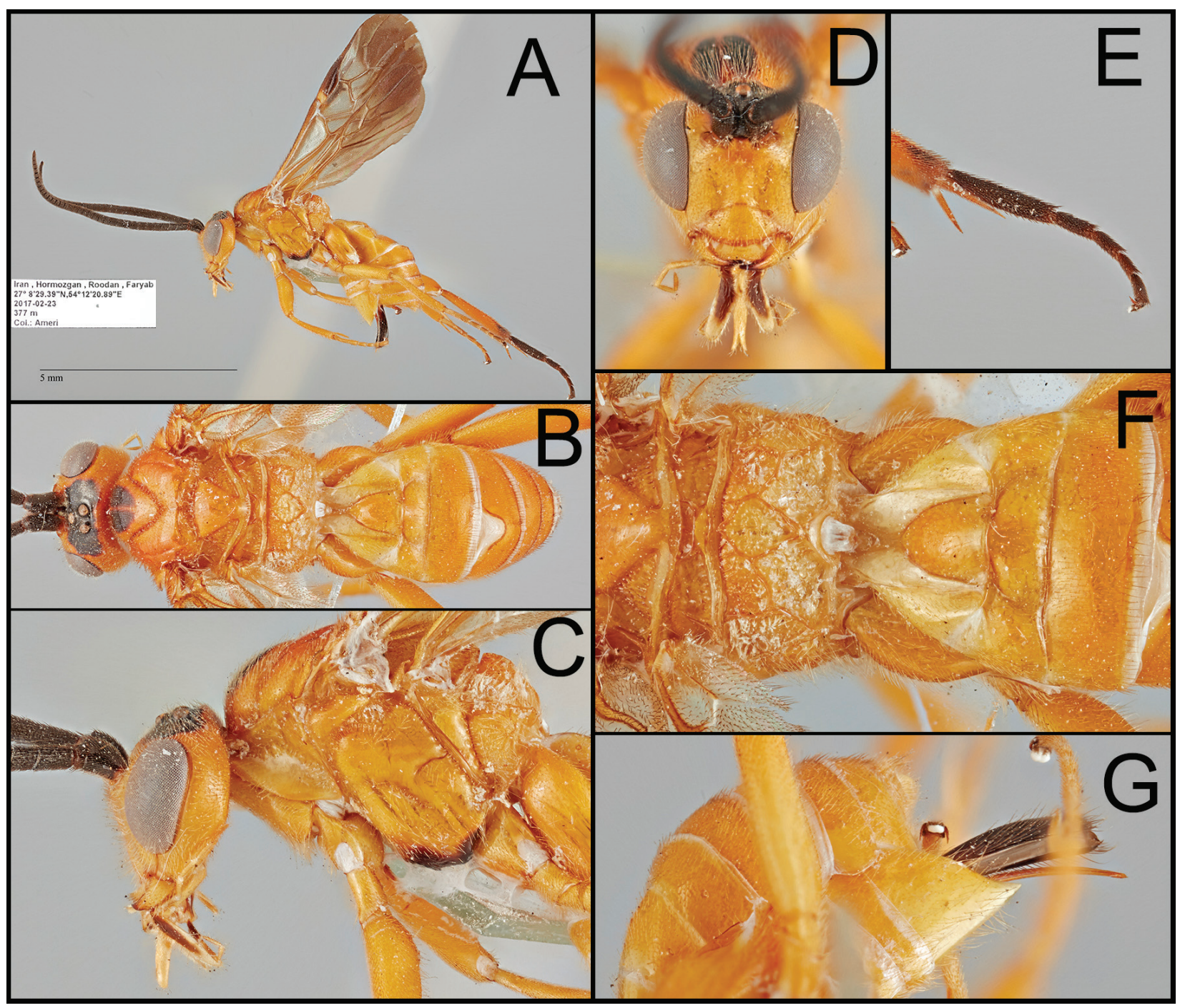

Figure 2. S. angustigena sp. nov. A. Lateral habitus; B. Dorsal habitus; C. Lateral head and mesosoma; D. Anterior head; E. Hind tarsus; F. Dorsal scutellum to T3; G. Ventro-lateral metanotum.

sp. nov. is similar to the Egyptian species, S. acrenulata (Fischer, 1958), but $S$. angustigena sp. nov. differs from $S$. acrenulata by possessing a greater number of antennomeres, pale upper face and glossa, pale scutellum and propodeum, relatively short hind tibial spur and long ovipositor sheath,

Description. Body 4.90-6.25 mm. Head. Eye densely setaceous with short interommatidial setae. Flagellum $33-36$-segmented. Length of gena $\sim 0.79 \times$ longer than eye length in lateral view (37:47) (Fig. 2C). POL $\sim 0.69 \times$ longer than diameter of anterior ocellus (9:13). Face mostly smooth, $\sim 1.01 \times$ longer than its width (84:83). Clypeus with two weakly developed tubercles; width of clypeus $\sim 2.06 \times$ longer than its length (70:34). Galea elongate $\sim 1.97 \times$ longer than clypeus height (67:34) (Fig. 2C, D). Mandible bidentate. $5^{\text {th }}$ maxillary palpomere $0.89 \times$ longer than apical palpomere (17:19). Mesosoma. Notauli entirely crenulate and acutely meeting at base (Fig. 2B). Scutellar sulcus broad, with 5 or 6 crenulae. Length of scutellum $0.97 \times$ longer than basal width of scutellum (68:70). Postscutellar depression crenulate, as long as anterior width of dorsellum. Dorsellum without median carina. Pronotum medially sculptured, carinate-rugose. Mesopleuron mostly smooth. Precoxal sulcus medially crenulate not reaching anterior and posterior margins of mesopleuron. Episternal scrobe shallow and wavy. Posterior mesopleural furrow entirely crenulate. Metapleuron anteriorly smooth, posteriorly rugose, groove between metepimeron and metepisternum crenulate. Propodeum mostly rugulose; propodeal spiracle ovoid; median areola of propodeum well defined with carinate margin, carinate margin narrowly meeting at both anterior margin of propodeum and nucha, its median width as long as its median length; transverse carina of propodeum medially strongly developed and reaching lateral margin of propodeum. Legs. Fore basitarsus $\sim 1.13 \times$ longer than combined length $2^{\text {nd }}-4^{\text {th }}$ tarsomeres (63:56). Mid-basitarsus as long as combined length of $2^{\text {nd }}-4^{\text {th }}$ tarsomeres $(70: 70)$. Maximum width of hind femur $\sim 1.72 \times$ longer than apical width of hind tibia (50:29); cup-like projection of hind tibia absent; basal spur on hind tibia $\sim 0.66 \times$ longer than basitarsus (71:107). Hind basitarsus laterally slightly expanded, but not expanded as in Hartemita Cameron, 1910, 1.13× longer than combined length $2^{\text {nd }}-4^{\text {th }}$ tarsomeres $(107: 94)$ 
(Fig. 2E). Claws pectinate with obtuse apical tooth. Wings. Forewing wing length: $\sim 5.71 \mathrm{~mm}$. Hind wing length: $\sim 4.66 \mathrm{~mm}$. Forewing apically infuscate; $1 \mathrm{r}$ absent; $3 \mathrm{r}$ basally spectrally present $(7 \circ, 1 \S)$ or absent $(1+)$; $3 \mathrm{RSb}$ broken basally, angled at basal third; second submarginal cell elongate; 1a absent. Hind wing infuscate mostly, hyaline at basal fourth; apically gradually darkened; $r$ entirely nebulous and pigmented; RS tubular at base, apically nebulous and pigmented; $\mathrm{M}+\mathrm{CU}$ apparently shorter than $1 \mathrm{M}$; $\mathrm{M}$ tubular at base, apically nebulous and entirely pigmented, gradually fading apically; 2-1A present as basal stump. Metasoma. T1 $\sim 1.14 \times$ longer than its apical width (83:73). T2 with a pair of curved submedian grooves, anteriorly deeply impressed, posteriorly gradually weakened (Fig. $2 \mathrm{~F}$ ), median length of T2 $0.53 \times$ longer than median length of T3 (31:59). Fourth and fifth metasomal sterna membranous posteriorly, medially unfolded. Hypopygium slightly impressed medially but unfolded, acute apically, its surface entirely sclerotized (Fig. 2G), its length $1.26 \times$ longer than its height in lateral view (88:70). Ovipositor sheath slightly downcurved and gradually expanding from base to apex, anteriorly bare posteriorly densely setose with long setae, length of protruded ovipositor sheath $\sim 0.53 \times$ longer than hind tibia (109:207). Ovipositor downcurved.

Male. Same as female except for body length and coloration. The body length of male is slightly shorter than females. The medial mesonotal lobe and ventral mesopleuron are pale in the male specimen.
Color. All specimens are mostly pale, and the following areas are melanic: antenna, vertex, frons, apical mandible, galea, median mesonotal lobe (mostly), ventral mesopleuron, inner hind tibia apically, apical hind tarsus, and ovipositor sheath. Wings apically infuscate, stigma mostly melanic except for base. Five specimens have a melanic mesonotal lobe and a pale ventral mesopleuron, however they share all other morphological characters with other members of $S$. angustigena.

Host. Unknown.

Distribution. Members of $S$. angustigena sp. nov. are known from Bandar Abbas, Minab and Rudan, as well as Abu Musa Island, Hormozgan, Iran (Fig. 3).

Etymology. From the Latin, angusti-, meaning "narrow" and gena, meaning "cheek".

\section{Schoenlandella deserta (Telenga, 1955)}

Cardiochiles desertus Telenga, 1955 (Telenga 1955).

Schoenlandella deserta (Telenga, 1955) (Dangerfield et al. 1999).

Description. See Telenga (1955), Oltra and Falco (1997), and Edmardash et al. (2018).

Host. Unknown.

Distribution. Members of Schoenlandella deserta (Telenga, 1955) are known from Azerbaijan, Egypt, Iran, Morocco, Spain, Turkmenistan, and Uzebekistan

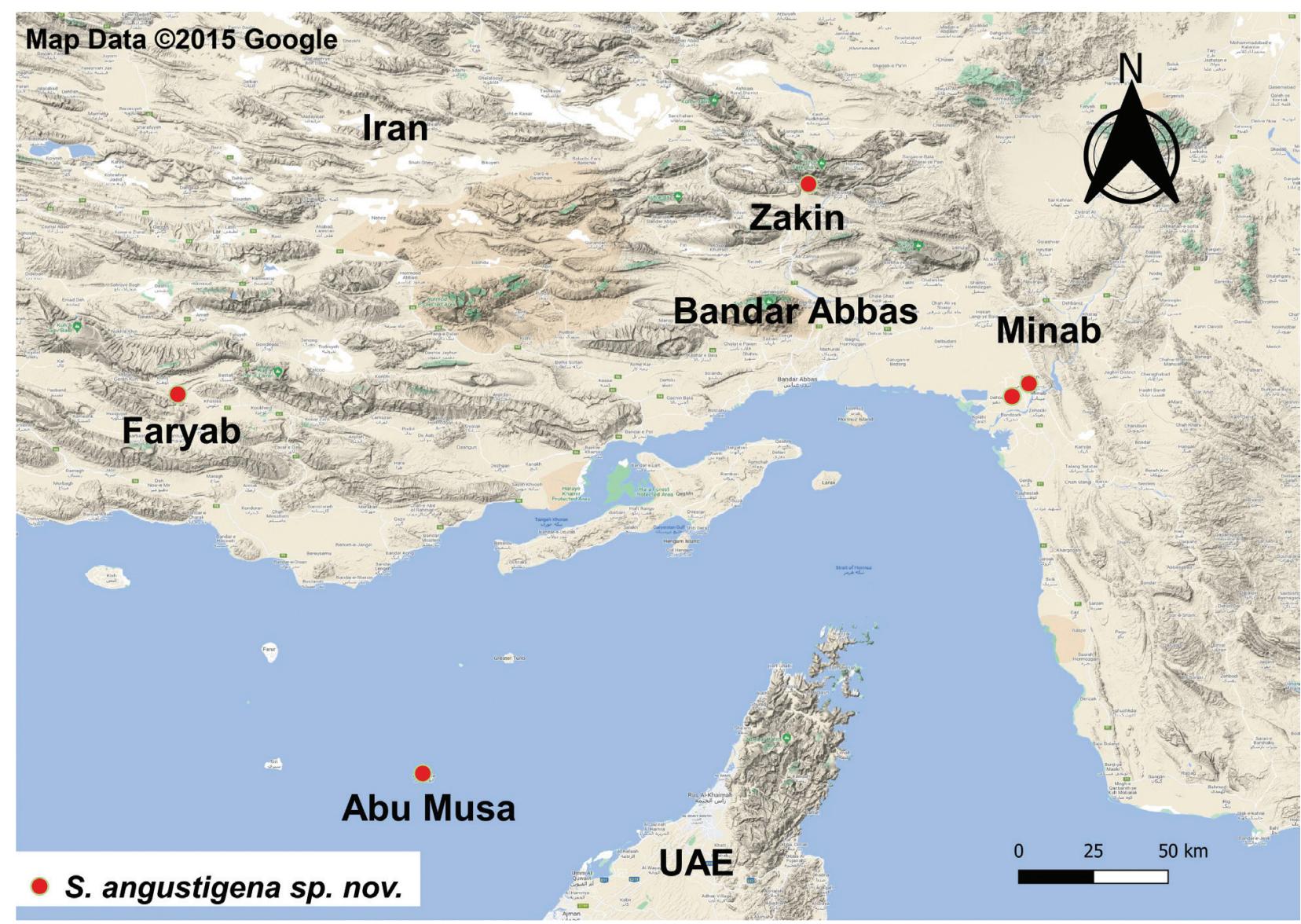

Figure 3. Distribution map of the members of S. angustigena sp. nov. in Iran. 
(Telenga 1955, Oltra and Falco 1997, Yu et al. 2016, Edmardash et al. 2018).

\section{Schoenlandella latigena Kang, sp. nov.}

http://zoobank.org/607DD3B2-B524-432A-A5F0-5692E1713B64 Fig. 4A-G

Material examined. Holotype: IRAN $\bullet+$, Bazyarai, Minab, Hormozgan; $27^{\circ} 10^{\prime} 36.83^{\prime \prime} \mathrm{N}, 57^{\circ} 2^{\prime} 12.44^{\prime \prime}$ E.; 34 m; 06. V. 2016; Col. Ameri. Paratypes: 1ㅇ, same as holotype except for the colleting date; 21. IV. 2016. $1 \delta^{\lambda}$, Boo moosa (Abu Musa), Hormozgan; 2552'52.37"N, 55¹'13.84"E; 9 m; 15. IV. 2016; Col. Ameri. 2ᄋ, Zakin, Bandar Abbas, Hormozgan; 2750'25.33"N, 56²18'12.33"E; 1176 m; 09. IV. 2016; Col. Ameri. 19, Mosaferabad, Roodan (Rudan), Hormozgan; 2744'50.62"N, 57²13'36.08"E; 459 m; 06. V. 2016; Col. Ameri.

Diagnosis. Members of Schoenlandella latigena sp. nov. are most similar to members of $S$. deserta (Telenga, 1955). Compared to members of $S$. deserta, members of $S$. latigena sp. nov. possess a more elongate gena (Fig. 4A) and a melanic stigma (Fig. 4F). In addition, they share crenulate notauli (Fig. 4B) and a sculptured metapleuron (Fig. 4A). Members of $S$. latigena sp. nov. are also similar to members of an Afrotropical species, S. variegata (Szepligeti, 1913). Members of these two species share densely setose eyes, broad face and clypeus, ventrally melanic mesopleuron, apically infuscate wings, and short and slightly expanded hind basitarsus. However, members of S. latige$n a$ sp. nov. can be distinguished from $S$. variegata by having relatively shorter interommatidial setae (Fig. 4C), narrower face, longer gena, longer hind basitarsus, and longer and unfolded hypopygium (Notes: Female members of $S$. variegata have a medially folded hypopygium.) (Fig. 4D).

Description. Body 6.25-6.45 mm. Head. Eye densely setaceous with short interommatidial setae. Antennomeres 32-33-segmented. Length of gena $\sim 1.12 \times$ longer than eye length in lateral view (47:42) (Fig. 4A). POL $\sim 1.27 \times$ broader than diameter of anterior ocellus $(11: 14)$. Face weakly sculptured, mostly finely punctate, $\sim 0.85 \times$ longer than its width (73:86). Clypeus with two strongly developed tubercles; width of clypeus $\sim 2.59 \times$ longer than its length (70:27). Galea elongated, $\sim 2.15 \times$ longer than clypeus height (58:27) (Fig. 4C). Mandible bidentate. Fifth maxillary palpomere as long as apical palpomere (15:15). Mesosoma. Notauli entirely crenulate and meeting acutely at base (Fig. 4B). Scutellar sulcus broad, with 6 or 7 crenulae. Length of scutellum $0.83 \times$ longer than basal width of scutellum (54:65). Postscutellar depression crenulate, as long as anterior width of dorsellum. Dorsellum with or without median carina. Pronotum medially sculptured, carinate-rugose. Mesopleuron mostly smooth. Precoxal sulcus medially moderately crenulate not reaching anterior and posterior margins of mesopleuron. Episternal scrobe shallow and wavy. Posterior mesopleural furrow entirely crenulate. Metapleuron anteriorly smooth, posteriorly rugose; groove between metepimeron and metepisternum crenulate. Propodeum mostly rugulose; propodeal spiracle ovoid; median areola of propodeum well defined with carinate margin, carinate margin narrowly meeting anteriorly, posteriorly reaching submedian of nucha, its median width as long as its median length, transverse carina of propodeum reaching lateral margin of propodeum. Legs. Fore basitarsus $\sim 0.90 \times$ longer than combined length $2^{\text {nd }}-4^{\text {th }}$ tarsomeres $(47: 52)$. Mid-basitarsus $\sim 0.89 \times$ longer

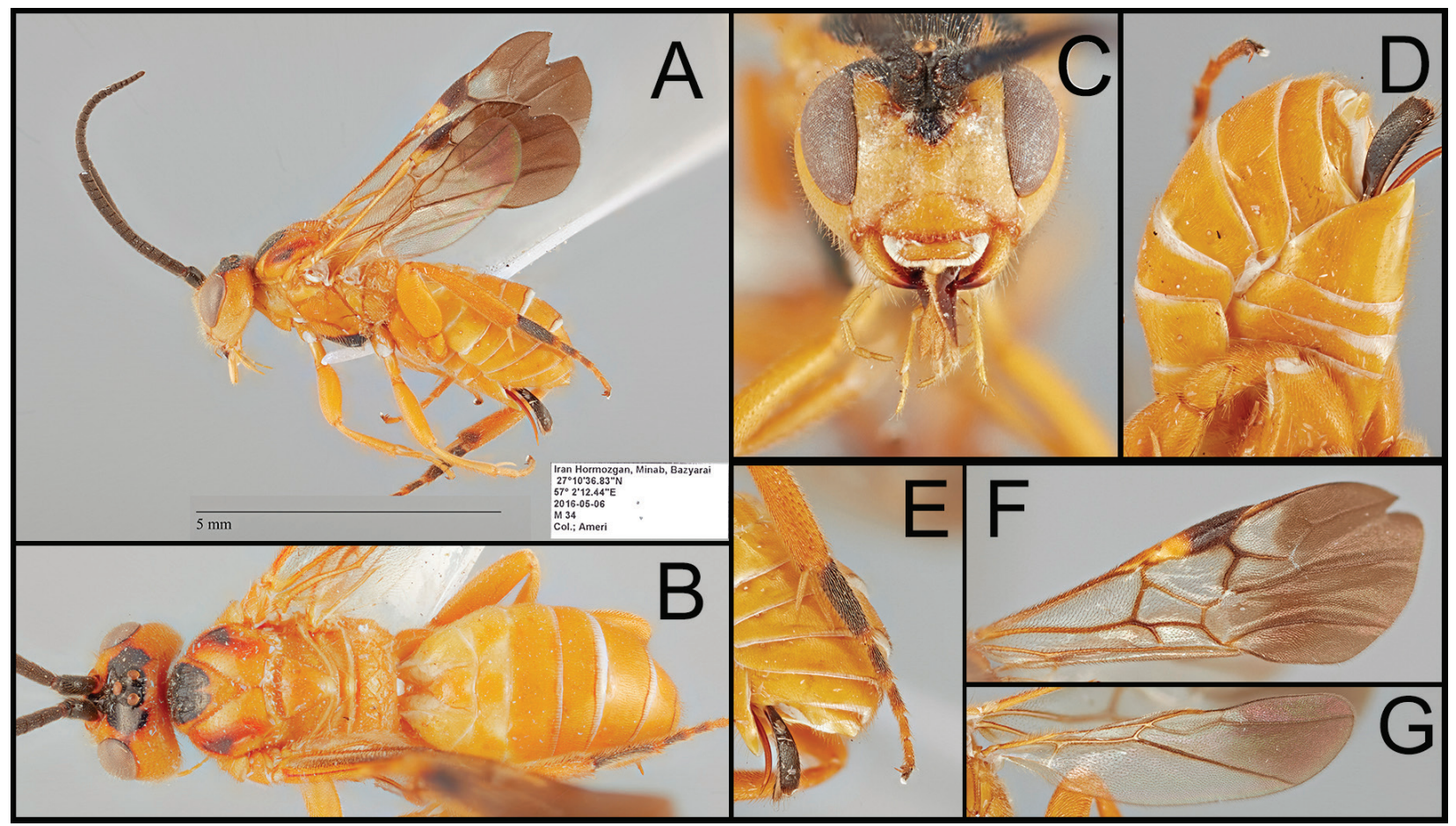

Figure 4. S. latigena sp. nov. A. Lateral habitus; B. Dorsal habitus; C. Anterior head and dorsal mesonotum; D. Ventro-lateral metanotum; E. Hind tarsus; F. forewing; G. hindwing. 


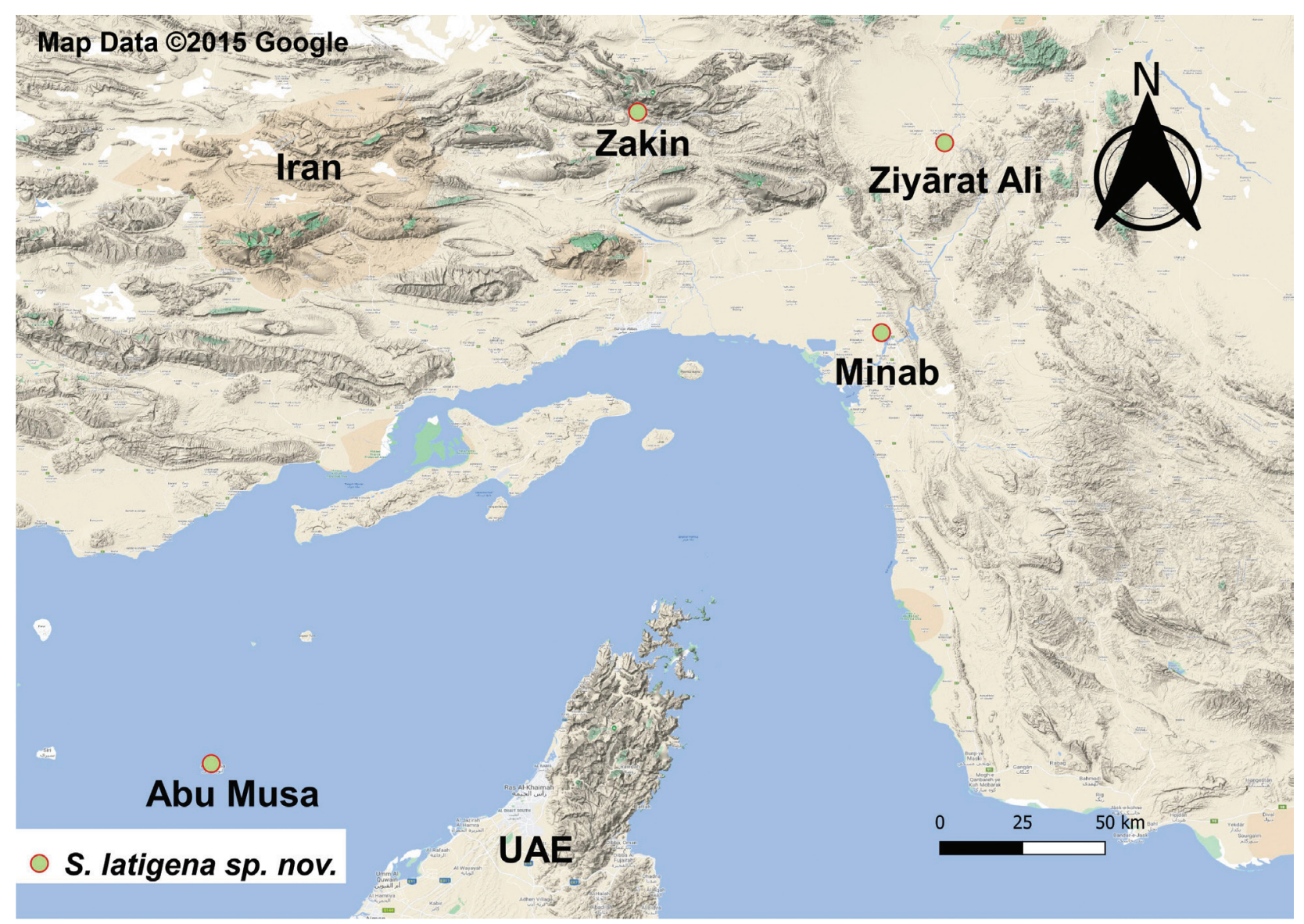

Figure 5. Distribution map of the members of S. latigena sp. nov. in Iran.

than combined length of $2^{\text {nd }}-4^{\text {th }}$ tarsomeres (54:61). Maximum width of hind femur $\sim 1.65 \times$ longer than apical width of hind tibia (51:31); cup-like projection of hind tibia absent; basal spur on hind tibia $\sim 0.74 \times$ longer than basitarsus (58:78). Hind basitarsus laterally slightly expanded, but not as expanded as Hartemita Cameron, 1910, 0.90× longer than combined length $2^{\text {nd }}-4^{\text {th }}$ tarsomeres $(79: 88)$ (Fig. 4E). Claws pectinate with obtuse apical tooth. Wings. Forewing wing length: $\sim 5.21 \mathrm{~mm}$. Hind wing length: $\sim 4.36 \mathrm{~mm}$. Forewing apically infuscate; $1 \mathrm{r}$ absent; $3 \mathrm{r}$ basally spectrally present $(3+)$ (Fig. $4 \mathrm{~F})$ or absent $(2 \bigcirc, 1 \precsim)$; 3RSb broken basally, angled at basal fourth; second submarginal cell elongated; 1a absent. Hind wing infuscate at apical third; $r$ entirely nebulous and pigmented; RS tubular at base, apically nebulous and pigmented; $\mathrm{M}+\mathrm{CU}$ apparently shorter than $1 \mathrm{M}$; M tubular at base, apically nebulous and pigmented, gradually fading apically; $2-1$ A present as basal stump. Metasoma. T1 $\sim 1.15 \times$ longer than its apical width (69:60). T2 entirely smooth, median length $\sim 0.70 \times$ longer than median length of T3 (38:54). Fourth and fifth metasomal sterna membranous posteriorly, medially unfolded. Hypopygium medially slightly impressed, acute apically, its surface anteriorly fully sclerotized medio-posteriorly less sclerotized (Fig. 4D), its length as long as its height in lateral view (90:90). Ovipositor sheath slightly downcurved and gradually expanding from base to apex, anteriorly bare, posteriorly densely setose with long setae; length of protruded ovipositor sheath $\sim 0.47 \times$ longer than hind tibia (92:196). Ovipositor downcurved.
Male. Same as female except for the following characters: antenna 33-segmented, scutellar sulcus with 8 crenulae, scutellum antero-medially with melanic spot, propleuron ventrally melanic, mesopleuron mostly melanic, hind coxa brown medially.

Color. Body mostly pale; the following areas are melanic: antenna, vertex, frons, apical mandible, galea, median mesonotal lobe mostly, lateral mesonotal lobe anteriorly, ventral mesopleuron, inner hind tibia apically, apical hind tarsus, ovipositor sheath. Wings apically infuscate, stigma apically melanic.

Host. Unknown.

Distribution. Members of Schoenlandella latigena sp. nov. are known from Bandar Abbas, Minab, and Rudan counties as well as Boo Moosa island, Hormozgan, Iran (Fig. 5).

Etymology. From the Latin, lati-, meaning "broad" and gena, meaning "cheek".

\section{Discussion}

The taxonomic status of Schoenlandella was discussed by Whitfield and Dangerfield (1997), Dangerfield et al. (1999), Mercado and Wharton (2003), Papp (2014), and Kang et al. (in prep.). Kang et al. (in prep.) treated Schoenlandella as a valid genus based on morphological data and using the phylogenetic data of Murphy et al. (2008). 
In Iran, members of $S$. deserta (Telenga, 1955) have been recorded only from Gulian province located in the north of Iran near the Azerbaijan-Iran border. From the samples collected in Hormozgan by AA, specimens of $S$. deserta were not found even though the species is distributed not only in Iran, but also in other countries. This may be a result of the mountainous nature of the region. The Zagros Mountain range stretches $\sim 1,600 \mathrm{~km}$ from the northwest to the south of the country, and the Alborz Mountain range stretches from the northwest to the northeastern of Iran. These two mountain ranges may play an important role in restricting the distribution of $S$. deserta in Iran. Of course, further collecting is needed to confirm their absence.

\section{Acknowledgements}

We extend appreciation to IRIPP for the loans of Iranian specimens and providing financial support for this research. We also thank Dr Karen Wright in TAMU for the loans of paratypes. IK is grateful to Dr Rodrigo Diaz and LSU AgCenter for their financial support as well as Dr Chris Carlton and Ms Victoria Bayless for friendship and improving English skills. IK also thanks Dr James Whitfield for sharing his knowledge of cardiochiline braconids.

\section{References}

Ashmead WH (1900) Classification of the Ichneumon Flies: or, the Superfamily Ichneumonoidea. Proceedings of the United States National Museum 23(1206): 1-220. https://doi.org/10.5479/si.00963801.23-1206.1

Cameron P (1905a) On the Hymenoptera of the Albany Museum, Grahamstown, South Africa (First paper). Record of the Albany Museum 1: 161-175.

Cameron P (1905b) On the phytophagous and parasitic Hymenoptera collected by Mr. E. Green in Ceylon. Spolia zeylanica 3: 67-143.

Cameron P (1910) On some Asiatic species of the subfamilies Spathiinae, Doryctinae, Rhogadinae, Cardiochilinae and Macrocentrinae in the Royal Berlin Zoological Museum. Wiener Entomologische Zeitschrift 29: 93-100. https://doi.org/10.5962/bhl.part.23337

Dangerfield PC, Austin AD, Whitfield JB (1999) Systematics of the world genera of Cardiochilinae (Hymenoptera: Braconidae). Invertebrate Systematics 13(6): 917-976. https://doi.org/10.1071/IT98020

Edmardash YA, Gadallah NS, Sharkey MJ (2018) Revision of the subfamily Cardiochilinae Ashmead, 1900 (Hymenoptera: Braconidae) in Egypt, with new records and a new species. Journal of Natural History 52(5-6): 269-297. https://doi.org/10.1080/00222933.2017.1420834

Gadallah NS, Ghahari H (2019) An updated checklist of Iranian Cardiochilinae, Rhyssalinae and Blacini (Hymenoptera: Ichneumonoidea: Braconidae). Oriental Insects 54(2): 143-161. https://doi.org/10.108 0/00305316.2019.1589592

Harris RA (1979) Glossary of surface sculpturing. Occasional Papers in Entomology 28: 1-31.

Huddleston T, Walker AK (1988) Cardiochiles (Hymenoptera: Braconidae), a parasitoid of lepidopterous larvae, in the Sahel of Africa, with a review of the biology and host relationships of the genus. Bulletin of entomological research 78(3): 435-461. https://doi. org/10.1017/S0007485300013201
Hymenoptera Anatomy Consortium (2021) The Hymenoptera Glossary. http://glossary.hymao.org [Accessed on 04 May 2021]

Kang I, Sharkey MJ, Diaz R (in prep.) Revision of the genus Schoenlandella (Hymenoptera: Braconidae: Cardiochilinae) in the New World, with a new species of a potential biological control agent for lepidopteran pests of bitter gourd (Momordica charantia L.). Manuscript submitted for publication.

Kriechbaumer J (1894) Hymenoptera ichneumonidea a medico nautico Dr. Joh. Brauns in itinere ad oras Africae occidentalis lecta. Berliner entomologische Zeitschrift 39: 297-318. https://doi.org/10.1002/ mmnd.18940390215

Mercado I, Wharton RA (2003) Mexican cardiochiline genera (Hymenoptera: Braconidae), including a preliminary assessment of species-groups in Toxoneuron Say and Retusigaster Dangerfield, Austin and Whitfield. Journal of Natural History 37(7): 845-902. https:// doi.org/10.1080/00222930110097167

Murphy N, Banks JC, Whitfield JB, Austin AD (2008) Phylogeny of the parasitic microgastroid subfamilies (Hymenoptera: Braconidae) based on sequence data from seven genes, with an improved time estimate of the origin of the lineage. Molecular phylogenetics and evolution 47(1): 378-395. https://doi.org/10.1016/j.ympev.2008.01.022

Nees von Esenbeck CG (1819) Appendix ad JLC Gravenhorst conspectum generum et familiarum Ichneumonidum, genera et familias Ichneumonidum adscitorum exhibens. Nova Acta Leopid. Carol. 9: 299-310.

Oltra MT, Falco JV (1997) The genus Cardiochiles (Hymenoptera: Braconidae) in the Iberian Peninsula. European Journal of Entomology 94: 295-300.

Papp J (2014) A revisional study on Szépligeti's cardiochiline type specimens deposited in the Hungarian Natural History Museum, Budapest (Hymenoptera, Braconidae: Cardiochilinae). Annales Historico-Naturales Musei Nationalis Hungarici 106: 169-214.

QGIS Development Team (2019) QGIS Geographic Information System. Open Source Geospatial Foundation Project. http://qgis.osgeo.org

Sanjerehei MM (2014) Conversion of life zone to ecologically less valuable land cover in Iran. Journal of Biodiversity and Environmental Sciences (JBES) 5(1): 544-554.

Sharkey MJ, Wharton RA (1997) Morphology and terminology. In: Wharton RA, Marsh PM, Sharkey MJ (Eds) Manual of the New World genera of the family Braconidae (Hymenoptera). Special Publication of the International Society of Hymenopterists, No 1, Washington DC, 19-37.

Szépligeti V (1911) Braconidae der I. Zentral-Afrika-Expedition. Wissenschaftliche Ergebnisse der Deutschen Zentral-Afrika Expedition 1907-1908, 3: 393-418.

Szépligeti V (1913) Neue afrikanische Braconiden aus der Ungarischen National-Museums. Annales historico-naturales Musei nationalis hungarici 11: 592-608.

Telenga, NA (1955) Braconidae: Microgastrinae, Agathinae [Translated from Russian by Israel Program for Scientific Translation, Jerusalem, 1964, 295 pp.]. Fauna of the U.S.S.R., Hymenoptera 5(4): 1-311.

Viereck HL (1914) Type species of the genera of ichneumon flies. US Government Printing Office 83: 1-186. https://doi.org/10.5479/ si.03629236.83.1

Whitfield JB, Dangerfield PC (1997) Subfamily Cardiochilinae. In: Wharton RA, Marsh PM, Sharkey MJ (Eds) Manual of the New World genera of the family Braconidae (Hymenoptera). International Society of Hymenopterists, Washington DC 1: 176-183.

Yu DS, van Achterberg CV, Horstmann K (2016) Taxapad 2016, Ichneumonoidea 2015. Database on flash-drive. Ottawa, Ontario. 